\title{
DESENVOLVIMENTO SUSTENTÁVEL: apontamentos sobre a relação entre o direito ao meio ambiente ecologicamente equilibrado e o conceito de desenvolvimento de Amartya Sen.
}

SUSTAINABLE DEVELOPMENT: notes about the conection between the right to ecologically balanced environment and the Amartya Sen's development concept.

\section{Carmem Letícia de Maia Pereira ${ }^{1}$}

\section{Resumo}

O presente trabalho tem como intuito analisar a compatibilidade da teoria de desenvolvimento criada por Amartya Sen com o direito ao desenvolvimento ecologicamente sustentável trazido pela Constituição Federal, e sob essa perspectiva estudar a possibilidade de um desenvolvimento sustentável embasado em tal teoria. $\mathrm{O}$ artigo foi escrito com base em revisão bibliográfica e tendo como referencial teórico o conceito de desenvolvimento para Amartya Sen. A relevância de tal artigo pode ser percebida pela crise econômica que o Brasil está passando e que, muitas vezes, faz aprovar medidas inconstitucionais com o discurso do crescimento econômico.

Palavras-chave: Amartya Sen; Desenvolvimento; Meio ambiente ecologicamente equilibrado; Sustentabilidade.

\begin{abstract}
The present work aims to analyze the compatibility of the development theory created by Amartya Sen with the right to ecologically sustainable development brought by the Federal Constitution, and from this perspective to study the possibility of sustainable development based on such theory. The article was written based on a bibliographical review and having as theoretical reference the concept of development for Amartya Sen. The relevance of this article can be perceived by the economic crisis that Brazil is going through and that, many times, does approve unconstitutional measures with the Discourse of economic growth.

Keywords: Amartya Sen; Development; Ecologically balanced environment;

\footnotetext{
${ }^{1}$ Mestranda em direito na Pontifícia Universidade Católica do Paraná (PUCPR); Graduada em direito pela Universidade Federal do Paraná (UFPR); Pesquisadora do Grupo Constitucionalismo e Democracia do PPGD/UFPR; Bolsista CAPES; Advogada.
} 
Saberes da Amazônia I Porto Velho, vol. 03, nº 06, Jan-Jun 2017.

Sustainability.

\section{INTRODUÇÃO}

O presente artigo aborda o enfrentamento dos direitos ao desenvolvimento, sob a perspectiva de Amartya Sen, e ao meio ambiente ecologicamente equilibrado, ambos assegurados como direitos fundamentais na Constituição Federal da República Federativa do Brasil, e se é possível implementar de fato um desenvolvimento sustentável sob tais perspectivas.

Inicialmente, analisa-se o meio ambiente como direito fundamental, a partir do reconhecimento de sua ligação com os direitos à vida, à saúde e ao bem-estar. Além disso, é feita uma análise de como esse direito tem o poder de restringir o Estado, no que concerne a agir levando em conta a tutela ambiental.

Em seguida, passar-se-á à análise da teoria de Amartya Sen sobre desenvolvimento. Para tal autor o desenvolvimento é um fenômeno histórico, no qual a humanidade foi conseguindo, aos poucos e não sem problemas, expandir sua liberdade. Para ele a expansão da liberdade é fim e meio do desenvolvimento de forma simultânea. Além disso, ainda que o crescimento econômico tenha um papel importante em sua teoria, ele não é fundamental para a expansão das liberdades, por isso, em países como Brasil, que estão tendo problemas com o crescimento do $\mathrm{PIB}$, isso não pode ser utilizado como desculpa para não se avançar o desenvolvimento.

$\mathrm{Na}$ terceira parte deste trabalho inicialmente é feita uma análise de algumas teorias sobre desenvolvimento sustentável e a compatibilidade delas com a teoria de desenvolvimento de Martya Sen. Após esse primeiro momento, é feito uma segunda análise de compatibilidade, com a teoria de desenvolvimento e as implicações trazidas pelo meio ambiente ecologicamente equilibrado. E por fim, é questionado como tais conceitos podem ser materializados e efetivados na realidade brasileira.

As presentes questões são levantadas sempre tendo em consideração o contexto e ralidade brasileira. A relevância de tal artigo encontra-se no atual momento social em que se encontra o Brasil, em que a crise econômica empurra 
medidas, muitas vezes inconstitucionais, para a aprovação com o discurso do crescimento econômico. Por vivermos em uma sociedade capitalista, que privilegia o que gera renda, a crise econômica acaba por ameaçar os mais diversos direitos, e entre eles também o direito a um meio ambiente ecologicamente equilibrado.

Desta forma, o presente artigo pretende mostrar que ainda que a Constituição tenha estabelecido o desenvolvimento como direito fundamental, ela também estabeleceu o direito ao meio ambiente, sendo fundamental lembrar que todos os direitos são interdependentes e inter-relacionados. Quando um direito é violado todos o são de alguma forma.

\section{O DIREITO FUNDAMENTAL AO MEIO AMBIENTE ECOLOGICAMENTE EQUILIBRADO}

O direito ao meio ambiente ecologicamente equilibrado era reconhecido, inicialmente, de forma indireta, ou seja, por sua ligação com os direitos à vida, à saúde e ao bem-estar. E por conta disso é considerado um prolongamento dos direitos humanos, como explica Antonio Augusto Cançado Trindade ao afirmar que o direito ao meio ambiente sadio representa "o direito às condições devida que asseguram a saúde física, moral, mental e social”2.

É importante dizer que quando é feita a referência ao direito humano à vida, reporta-se a vida digna e a dignidade humana, ambas como base emancipatória. Assim, o direito ao meio ambiente deve ser pensado nesse contexto, como fundamental à proteção do direito humano à vida digna.

$\mathrm{Na}$ Carta Constitucional de 1988 os direitos fundamentais não estão previstos de forma exaustiva no art.5ํㅡㄴ mas como é o caso do direito ao meio ambiente ecologicamente equilibrado, encontram-se expressamente também em outras partes do texto constitucional.

O direito ao meio ambiente ecologicamente equilibrado é materialmente fundamental, já que é uma extensão do direito à vida, conferido a todos os seres humanos e cuja proteção é determinada como dever a toda sociedade e ao Poder Público e, por óbvio que a ele se estendem todas as prerrogativas inerentes a esta fundamentalidade, especialmente a sua aplicabilidade imediata e sua sitemas de Proteção Internacional. Porto Alegre: Sergio Antonio Fabris, 1993, p.24. 
Saberes da Amazônia | Porto Velho, vol. 03, nº 06, Jan-Jun 2017.

imodificabilidade até mesmo por Emenda Constitucional, já que é cláusula pétrea nos termos do art.60, §4ำ da Constituição Federal.

O estabelecimento constitucional do meio ambiente ecologicamente equilibrado como essencial a qualidade de vida traz em si um alargamento da visão antropocêntrica do direito, já que não mais se vê o homem isolado da natureza, mas com a necessidade de mantê-la para manter a si. O constituinte buscou na expressão "ambiente ecologicamente equilibrado" um equilíbrio de forças díspares, reservando espaço especial para a prevenção e precaução de danos futuros ${ }^{3}$.

Além disso, o estabelecimento do meio ambiente como direito fundamental não mais tem em si apenas a ideia de obrigações negativas para o Estado, de abstenção frente a liberdades individuais, mas mais comumente impõe obrigações positivas ao Poder Público para a implementação desses direitos, já que são a base do Estado Social de Direito. José Afonso da Silva, na sua definição de fundamentalidade, demonstra de forma exemplar a razão do meio ambiente se enquadra em tal categoria de direitos: "trata de situações jurídicas sem as quais a pessoa humana não se realiza, não convive e, às vezes, nem mesmo sobrevive; fundamentais do homem no sentido de que todos, por igual, devem ser, não apenas formalmente reconhecidos, mas concreta e materialmente efetivados" ${ }^{4}$.

Mesmo na jurisprudência não há mais dúvidas quanto à fundamentalidade do direito ao meio ambiente ecologicamente equilibrado, pois ainda em 1995 o Supremo Tribunal Federal proferiu duas decisões, ambas relatadas pelo Ministro Celso de Mello, que consagram tal direito como fundamental. Na decisão em face de Mandado de Segurança 22.164-0/SP este direito também foi consagrado como de titularidade difusa e expressão do princípio da solidariedade ${ }^{5}$.

Canotilho destaca que quando o constituinte elevou o meio ambiente a direito fundamental, também o consagrou como bem constitucional e por conta disso, "os vários decisores (legislador, tribunais, administração) devem tomar em

3 FERREIRA, Heline Sivini. LEITE, José Rubens Morato. A expressão dos objetivos do Estado de Direito Ambiental na Constituição Federal de 1988. In: COUTINHO, Ronaldo; AHMED, Flávio. Cidade, direito e meio ambiente: perspectivas críticas. Rio de Janeiro: Lumen Juris, 2011.p.50.

4 SILVA, José Afonso da. Curso de Direito Constitucional Positivo. 22. ed. São Paulo:Malheiros, 2003, p.178.

5 STF - MS 22.164 - Rel. Min. Celso de Mello - Distrito Federal - j. em 17.11.1995. Disponível em: <http://www.stf.gov.br/jurisprudencia>. Acesso em 10 nov. 2016. 
conta na solução de conflitos constitucionais esta reserva constitucional do bem ambiente" ${ }^{\text {. }}$ O Poder Público deve conduzir todas as suas políticas públicas ambientais à concretização progressiva e gradual do direito ao meio ambiente ecologicamente equilibrado, e deve sempre atentar para que a regressão e o retrocesso não ocorram, mas junto ao Estado, toda sociedade também tem o dever de zelar por tal direito de forma a garantir às presentes e futuras gerações uma sadia qualidade de vida.

O direito em questão além de imprimir deveres positivos e negativos ao Poder Público, também o vincula, tendo em vista que é direito fundamental previsto na Constituição. Ingo Wolfegang Sarlet e Tiago Fenstersifer explicam o que isso quer dizer exatamente: "que os deveres de proteção ambiental conferidos ao Estado vinculam os poderes estatis de tal modo a limitar a sua liberdade de conformação na adoção de medidas atinentes à tutela do ambiente"”.

É possível dizer que foi com a constituição de 1988 que se inaugurou uma ordem pública ambiental constitucionalizada ${ }^{8}$, trazendo a substituição do princípio civilístico/administrativo tradicional regente do Estado liberal, pelo dever genérico de defesa e preservação do meio ambiente, que deve ser observado não só pelo Poder Público, como também pela sociedade, juntamente com os princípios que estatuem a primariedade do meio ambiente e a exploração limitada da propriedade.

Desta forma, a Constituição ao consagrar o direito ao meio ambiente ecologicamente equilibrado como direito fundamental, de inaugurando um modelo de Estado socioambiental, atribui diversas obrigações positivas ao Poder Público. Em coerência a isso o Estado abandona a inércia, típica de Estados liberais, e recebe deveres de um Estado intervencionista, ao qual se atribuem ações afirmativas específicas, cuja efetivação e observância são basilares para uma verdadeira ordem pública ambiental.

É possível aferir assim, que o Estado de Direito Social, composto pelo Estado de direito Ambiental, submete a ordem privada a uma ordem pública

6 CANOTILHO, J.J. Gomes. Direito Constitucional Ambiental Português e da União Europeia. In: CANOTILHO, José Joaquim Gomes; LEITE, José Rubens Morato (Orgs.). Direito Constitucional Ambiental Brasileiro. São Paulo: Saraiva, 2007, p.5.

7 SARLET, Ingo Wolfgang. FENSTERSEIFER, Tiago. Estado socioambiental e mínimo existencial (ecológico?): alguns aproximações. In: SARLET, Ingo Wolfgang (Org.). Estado Socioambiental e Direitos Fundamentais. Porto Alegre: Livraria do Advogado, 2010, p.17.

8 BENJAMIN, Antonio Herman V. Constitucionalização do Ambiente e Ecologização da Constituição Brasileira. In CANOTILHO, José Joaquim Gomes; LEITE, José Rubens Morato (Orgs.). Direito Constitucional Ambiental Brasileiro. São Paulo: Saraiva, 2007, p.121-124. 
Saberes da Amazônia | Porto Velho, vol. 03, nº 06, Jan-Jun 2017.

hierarquicamente superior guiada pelos objetivos e mandamentos constitucionais. Isso gera uma alteração profunda na ordem social, "pois significa colocar o públicoambiental não como limite externo ao privado-ambiental, mas como pressuposto norteador da própria estrutura, legitimidade e funcionamento da exploração dos recursos naturais, resultado da posição logicamente antecedente e constitucionalmente prevalente do regime público"'.

Isso tudo significa também, que o conteúdo da dignidade humana deve abranger, além da dimensão social, uma dimensão ambiental, que torna obrigatória a harmonização entre a tutela dos direitos ambientais e sociais em um projeto de desenvolvimento ${ }^{10}$. Consequentemente, a falta de acesso a direitos básicos a maior parte da população e a desigualdade social, integram a problemática ambiental em uma relação de causa e efeito recíproca. $\mathrm{O}$ descumprimento dos direitos sociais básicos é fator que contribui para a contínua degradação ambiental e risco de exterminação de recursos ambientais e ecossistemas. Enquanto de outro lado, a deterioração ambiental e a potencialização dos riscos ambientais também afetam a sadia qualidade de vida das pessoas e, por consequência, a dignidade humana.

Por fim, é relevante destacar que ao colocar a expressão "sadia qualidade de vida" na Constituição, no art. 225, caput, aponta o dever do Estado e o direito dos cidadãos, de garantirem condições mínimas para viver com dignidade e bem-estar com possibilidades de atingir o desenvolvimento pleno. ${ }^{11}$ Posto isso, fica evidente que a Constituição não apenas pretende proteger o meio ambiente ecologicamente equilibrado, mas também impõe a si o dever de desenvolver seus cidadãos. E a questão que se coloca aqui é se o conceito de desenvolvimento trazido por Amartya Sen seria o ideal para conciliar esses dois direitos e deveres constitucionais.

\section{O CONCEITO DE DESENVOLVIMENTO PARA AMARTYA SEN}

9 BENJAMIN, Antonio Herman V. Constitucionalização do Ambiente e Ecologização da Constituição Brasileira. In CANOTILHO, José Joaquim Gomes; LEITE, José Rubens Morato (Orgs.). Direito Constitucional Ambiental Brasileiro. São Paulo: Saraiva, 2007, p.123-124.

10 SARLET, Ingo Wolfgang. FENSTERSEIFER, Tiago. Estado socioambiental e mínimo existencial (ecológico?): alguns aproximações. In: SARLET, Ingo Wolfgang (Org.). Estado Socioambiental e Direitos Fundamentais. Porto Alegre: Livraria do Advogado, 2010, p.13.

11 BENJAMIN, Antonio Herman V. Constitucionalização do Ambiente e Ecologização da Constituição Brasileira. In CANOTILHO, José Joaquim Gomes; LEITE, José Rubens Morato (Orgs.). Direito Constitucional Ambiental Brasileiro. São Paulo: Saraiva, 2007, p.108. 
Amartya Sen faz uma distinção entre tipos de atitude quanto ao processo de desenvolvimento ${ }^{12}$ :

1) desenvolvimento como um processo feroz, sabedoria como sinônimo de dureza, e negligência de preocupações "frouxas" (nesse grupo são incluídas, fornecimento de serviços sociais para a população, favorecimento cedo demais de direitos políticos e civis, além da própria democracia). Essas preocupações "frouxas" podem ganhar lugar depois que o desenvolvimento tiver dado alguns frutos, até lá é "dureza e disciplina". As diversas teorias que compartilham dessa visão variam quais as preocupações "frouxas" que devem ser evitadas.

2) desenvolvimento como um processo amigável. Há versões em que considera que o prazer do processo de desenvolvimento pode ser reconhecido pelas trocas mutualmente benéficas, por liberdades políticas, desenvolvimento social, ou ainda uma combinação destas.

Ele se posiciona favorável a segunda visão e tenta ver o desenvolvimento como "um processo de expansão das liberdade reais que as pessoas desfrutam." ${ }^{13} \mathrm{E}$ nisso a liberdade possui dois papeis, 1 ) constitutivo = fim primordial; 2) papel instrumental $=$ principal meio do desenvolvimento .

O fim constitutivo se relaciona com as liberdades substantivas (saber ler, não ter fome, etc.). Na perspectiva constitutiva o desenvolvimento é o processo de expansão dessas e de outras liberdades, e a avaliação desse fim primordial deve ser sempre baseada nisso.

Nas visões mais estreitas de desenvolvimento (baseadas na industrialização ou no PNB) é comum se questionar se a liberdade de participação/dissensão política é ou não conducente ao desenvolvimento. Ao ver o desenvolvimento como liberdade isso parece não fazer sentido, já que esses são partes constitutivas do desenvolvimento. (até quem é rico estaria sendo privado de algo relevante). No processo de desenvolvimento (quando visto pela ampliação da liberdade humana) é fundamental que se eliminem todas as privações das pessoas. Mesmo que ainda não diretamente interessadas, elas devem ter o poder de escolher. Assim, o

12 SEN, Amartya. Desenvolvimento como liberdade. São Paulo: Companhia das Letras, 2000, p.

13 SEN, Amartya. Desenvolvimento como liberdade. São Paulo: Companhia das Letras, 2000, p. 
Saberes da Amazônia | Porto Velho, vol. 03, nº 06, Jan-Jun 2017.

desenvolvimento como liberdade ${ }^{14}$ não pode deixar de levar em conta as privações, que devem ser levadas em conta na sua relevância em si, não nos efeitos que causam a outras características do desenvolvimento. Desta forma, é importante que tenhamos em mente que essas liberdades podem sim ser instrumentos para o progresso econômico, o que não reduz a sua importância como fim do desenvolvimento.

A liberdade como meio do desenvolvimento diz respeito a como diferentes tipos de direitos, oportunidades e intitulamentos ${ }^{15}$ ajudam para uma expansão da liberdade humana, e por consequência do desenvolvimento. $E$ isso vai além do que dizer que cada tipo de liberdade tem que contribuir para o desenvolvimento, já que este é também um processo de crescimento da liberdade humana. A eficácia da liberdade como instrumento está no fato de que as liberdades possuem uma interrelação e que uma pode contribuir para o desenvolvimento da outra.

Para a teoria de Amartya Sen existem 5 tipos de liberdade que merecem destaque numa perspectiva instrumental ${ }^{16}$. Não é uma lista exaustiva, mas aponta uma base que deve ser levada em conta na análise de questões políticas. Elas contribuem para a pessoa viver mais livremente, mas também completam umas as outras. Para o autor, compreender os encadeamentos empíricos que vinculam os tipos distintos de liberdade são fundamentais pra compreender o papel instrumental da liberdade, tendo em vista que o argumento de que a liberdade não é apenas o objetivo do desenvolvimento, mas também seu principal meio, esta diretamente ligado $a$ isso.

1) liberdades políticas (inclui direitos civis): diz respeito as oportunidades que as pessoas têm de escolher quem irá governá-las e sob quais princípios, além de possibilidade de fiscalização e crítica dessas autoridades.

2) facilidades econômica: oportunidades que os indivíduos têm de utilizar recursos econômicos com propósitos de consumo, produção e troca. Quando o 14 SEN, Amartya. Desenvolvimento como liberdade. São Paulo: Companhia das Letras, 2000, p. 56.

15 Intitulamento de pessoa é definido pelo conjunto de pacotes alternativos de bens que podem ser adquiridos por uma pessoa, pelos diversos canais legais de aquisição possibilitados a essa pessoa. Pacote de bens originais que ela possui dotação mais o pacote de bens alternativos que ela pode adquirir pelo comércio e produção entitlement de troca. Ex. Uma pessoa passa fome quando seu intitulamento não inclui nenhum pacote de bens que contenha quantidade adequada de comida. SEN, Amartya. Desenvolvimento como liberdade. São Paulo: Companhia das Letras, 2000, p. 57.

16 SEN, Amartya. Desenvolvimento como liberdade. São Paulo: Companhia das Letras, 2000, p. $58-60$ 
processo de desenvolvimento econômico aumenta a riqueza de um país, estas refletem no aumento de intitulamentos econômicos dos indivíduos. E nesse caso é importante levar em conta as considerações distributivas, já que a forma como as rendas adicionais são distribuídas faz toda a diferença.

3) oportunidades sociais: são as disposições nas áreas de saúde, educação, etc. Que afetam a liberdade substantiva do indivíduo. São fundamentais não apenas para a vida privada (vida saudável), como também para a participação da vida política e econômica.

4) garantias de transparência: Nas interações sociais os indivíduos se relacionam pensando no que lhes está sendo oferecido e no que eles podem obter, desta forma a sociedade opera sobre certa base de confiança. As garantias de clareza tem papel instrumental como inibidoras da corrupção, da irresponsabilidade financeira e de transações ilícitas.

5) segurança protetora: diz repeito a como opera um sistema econômico, que muitas vezes levas pessoas já vulneráveis a situações ainda piores. Por isso, proporciona uma rede de segurança social, impedindo que a população afetada seja levada a miséria. Ela inclui disposições institucionais fixas, como benefícios aos desempregados, suplementos de renda, etc.

Essas liberdades aumentam diretamente a capacidade das pessoas, mas também se suplementam e reforçam umas as outras, o que fundamental saber para abordas as políticas de desenvolvimento. O crescimento econômico deve ser analisado não apenas pelo aumento de rendas privadas, mas também na expansão dos serviços sociais, já que pode contribuir para a seguridade social, intervenção governamental ativa na sociedade, etc.

O autor diz ${ }^{17}$ que a criação de oportunidades sociais por meio de saúde, educação, imprensa livre etc., contribui para o desenvolvimento econômico e para redução das taxas de mortalidade, que por consequência diminuem as taxas de natalidade, que mostram a relevância da educação básica, especialmente das mulheres. $O$ autor cita o exemplo do Japão (taxas de alfabetização elevadas desde antes da industrialização) que teve seu desenvolvimento econômico diretamente relacionado com o desenvolvimento de recursos humanos. Esse caso abala a ideia de que esse desenvolvimento humano (processo de expansão da educação, saúde,

17 SEN, Amartya. Desenvolvimento como liberdade. São Paulo: Companhia das Letras, 2000, p. 61. 
Saberes da Amazônia | Porto Velho, vol. 03, n 06, Jan-Jun 2017.

etc.) é um luxo que só pode ser adquirido após o desenvolvimento. O Leste Asiático buscou antes a expansão em massa da educação, depois dos serviços de saúde, e o fizeram antes de romper com a pobreza, o que gerou ótimos resultados.

Para essa teoria a relevância que as liberdades individuais possuem no processo de desenvolvimento, gera a necessidade de uma maior atenção nas influências sociais que contribuam para determinar a natureza e o alcance delas. Essas liberdades são influenciadas de um lado pela garantia social das liberdades, tolerância e possibilidade de troca, e por outro pelo apoio público as facilidades(saúde, educação, etc).

É comum, segundo Amartya $S e n^{18}$, se descartar a análise de renda per capta com a longevidade, já que a ligação entre elas é muito evidente, porém é fundamental uma análise mais atenta no que concerne às disposições sociais. $O$ autor cita pesquisa recente realizada, que mostra que de fato há essa relação entre PNB per capta e a expectativa de vida, mas que ela se verifica de forma mais clara quando analisado o impacto do PNB sobre 1) as rendas, principalmente a dos pobres; 2) gastos públicos, especialmente saúde. Com esses dados como variáveis explicativas por si, a relação de PNB per capta e longevidade não faz mais tanto sentido. Essa pesquisa não quer dizer que a expectativa não cresce com o aumento do PNB per capta, mas apenas que essa relação funciona por meio do investimento em saúde e eliminação da pobreza. O ponto mais relevante disso é que o impacto do crescimento econômico vai depender de como seus frutos são utilizados.

Exemplo disso é o Leste Asiático em que "a expansão de oportunidades sociais serviu para facilitar o desenvolvimento econômico com alto nível de emprego, criando também circunstâncias favoráveis para a redução das taxas de mortalidade e para o aumento da expectativa de vida"19. Já nos países que não investem em recursos sociais, como o Brasil, essa relação com a longevidade vem aparecendo bem mais lentamente.

Para Amrtya Sen os países que investem em processos de desenvolvimento conduzidos pelo custeio público são uma realidade complexa, tendo em vista a falta de recursos em tais países, motivo usado por outros países, inclusive, para que não

18 SEN, Amartya. Desenvolvimento como liberdade. São Paulo: Companhia das Letras, 2000, p. 65-66.

19 SEN, Amartya. Desenvolvimento como liberdade. São Paulo: Companhia das Letras, 2000, p. 67. 
se invista em áreas como saúde e educação até que se obtenha certo grau de riqueza econômica ${ }^{20}$. Esses países pobres conseguem investir em serviços sociais relevantes, pois estes são compostos em grande parte por trabalho-intensivos, e já que os salários são baixos eles acabam saindo baratos. Numa economia pobre há menos dinheiro, mas também é necessário menos dinheiro para realizar algo. Então os preços e custos relativos tem certa relevância, e mostra que muito se depende do comprometimento com os serviços sociais relevantes.

Para a teoria do autor é certo que o processo mediado pelo crescimento é mais vantajoso que o de condução pelo custeio público, já que pode oferecer mais, pois ainda há vários tipos de limitações ligados a baixa renda. Deve-se questionar a razão dos países como Kerala mesmo obtendo grande êxito no desenvolvimento humano não conseguem ampliar isso pra renda, tornando o êxito mais completo. $E$ isso precisa ser analisado do ponto de vista das políticas econômicas de incentivos e investimentos. Assim, o êxito conduzido pelo custeio público realiza menos que o pelo crescimento, no qual o crescimento econômico e a melhora da qualidade de vida tendem a andar juntos.

Por outro lado esse sucesso do custeio público mostra que o Estado não precisa esperar o crescimento econômico para investir nos serviços sociais fundamentais, podendo melhorar a qualidade de vida antes disso, sendo inclusive um ótimo meio para melhorar de forma rápida essa qualidade. Contudo, é também um ótimo argumento para ir além, e praticar políticas mais amplas que incluem crescimento econômico e a elevação das características clássicas da qualidade de vida $^{21}$

Por fim, é possível dizer que para Amartya Sen a expansão da liberdade humana deve ser fim e meio do desenvolvimento. $O$ objetivo de desenvolvimento está ligado a como as pessoas desfrutam suas liberdades. E desta forma, quando se instituem disposições institucionais deve-se sempre levar em conta os papéis instrumentais das liberdades. Estes incluem vários componentes distintos, porém inter-relacionados, que possuem fortes encadeamentos entre si.

20 SEN, Amartya. Desenvolvimento como liberdade. São Paulo: Companhia das Letras, 2000, p.

21 SEN, Amartya. Desenvolvimento como liberdade. São Paulo: Companhia das Letras, 2000, p. 


\section{DESENVOLVIMENTO SUSTENTÁVEL: MITO OU CONSENSO ENTRE DOIS DIREITOS?}

José Eli Veiga, em seu texto a emergência socioambiental, apresenta três teorias $^{22}$ que relacionam o meio ambiente e o desenvolvimento, apresentando teorias do chamado desenvolvimento sustentável. Através da análise dessas teses combinadas com a ideia de Amartya Sen sobre desenvolvimento, será possível dizer se o conceito de desenvolvimento apresentada pelo autor é compatível com o direito ao meio ambiente equilibrado que a Constituição brasileira traz em si.

É importante dizer que desenvolvimento sustentável é um termo amplo, o qual Baroni ${ }^{23}$ conseguiu classificar ao menos 11 definições para esse tema, que pela amplitude acaba sendo adaptado pelo grupo que "compra o termo", como aconteceu rapidamente com os empresários. Um exemplo disso é o resultado da pesquisa feita pela agência americana de marketing ambiental Terra Choice, que visa descobrir quantos dos produtos que se declaram verdes são realmente sustentáveis. De acordo com pesquisa realizada em $2010,95,5 \%$ das empresas pesquisadas comete o chamado greenwashing (lavagem cerebral verde), prática em que os danos ambientais são escondidos dos clientes ${ }^{24}$.

No entanto, por questões metodológicas, o presente trabalho se restringirá as três teorias apresentadas por José Eli Veiga. A primeira corrente ${ }^{25}$ entende que não é mais possível continuar a viver da forma como vivemos, porém percebe uma saída na adoção da "condição estacionária". Seu principal formulador, Herman E. Daly, faz a comparação com uma biblioteca abarrotada, os gestores da biblioteca podem decidir que mais nenhum livro seja incorporado ao acervo ou ainda, que apenas entrarão novos livros, que sejam melhores que os já existentes, se a mesma quantia seja desfeita. Ela não está crescendo quantitativamente, mas qualitativamente. Trazendo par a realidade, seria a possibilidade de tornar a matriz energética de um país renovável, sem aumentar o PIB.

22 VEIGA, José Eli da. A emergência socioambiental. São Paulo: Senac, 2007, p.94-97.

23 BARONI, Margaret. Ambigüidades e deficiências do conceito de desenvolvimento sustentável.

RAE - Revista de Administração de Empresas, 1992, p.16.

24 GALILEU. Disponível em: < http://revistagalileu.globo.com/Revista/Common/0,ERT21417817773,00.html . Acesso em: 10 nov. 2016.

25 VEIGA, José Eli da. A emergência socioambiental. São Paulo: Senac, 2007, p.95-96. 
A segunda teoria ${ }^{26}$ vincula a melhoria das condições ambientais do país ao seu enriquecimento medido pela renda per capita. O autor diz que já houve demonstração empírica de que nas fases iniciais de desenvolvimento há uma grande deterioração ambiental, mas quando se atinge a marca de 8 mil dólares per capta a sociedade passa a dar mais valor a conservação e recuperação desses ecossistemas. E esse dado reforçaria a teoria de desenvolvimento que acredita ser possível intercambiar recursos naturais, recursos humanos e capitais, buscando equilibrar as contas nacionais com a sustentabilidade.

A terceira ${ }^{27}$ e última, vai dizer que cada geração deve legar à sua sucessora pelo menos tanta riqueza per capta quanto ela própria herdou. Isso em termos de conhecimento, recursos naturais, habilidades, etc. Assim, o desenvolvimento deveria ser riqueza per capta (que inclui esses conceitos) e não PIB per capta.

Analisando as três correntes de desenvolvimento sustentável apresentada por José Eli da Veiga, logo de antemão é possível perceber que a teoria de Amartya Sen é incompatível com pelo menos um dos conceitos de desenvolvimento sustentável.

A teoria trazida por Amartya Sen traz a expansão das liberdades como sinônimo de desenvolvimento, mas no processo, em que a "liberdade é simultaneamente o principal fim e o principal meio do desenvolvimento, é inegável o papel desempenhado pelo crescimento econômico"28. Ainda que não haja sincronia entre os dois (liberdades e crescimento econômico), não é possível pensar essa teoria sem pensar na elevação de efetivo de um país, o que contraria completamente a primeira teoria de desenvolvimento sustentável apresentada.

Já a segunda teoria de desenvolvimento sustentável que vincula renda com cuidado com o meio ambiente seria mais compatível com a apresentada por Amartya Sen, tendo em vista que a expansão das liberdades, e, por conseguinte do desenvolvimento, chegaria a tal ponto que o meio ambiente seria uma das únicas preocupações da população.

No entanto, se ela compatível com a ideia de desenvolvimento de Amartya Sen, ela não é com a exposta na Constituição brasileira, que como exposto na primeira parte deste artigo, tem o meio ambiente ecologicamente equilibrado como

26 VEIGA, José Eli da. A emergência socioambiental. São Paulo: Senac, 2007, p.94-95.

27 VEIGA, José Eli da. A emergência socioambiental. São Paulo: Senac, 2007, p.96-97.

28 VEIGA, José Eli da. A emergência socioambiental. São Paulo: Senac, 2007, p.94. 
Saberes da Amazônia | Porto Velho, vol. 03, no 06, Jan-Jun 2017.

um direito fundamental de aplicação imediata, não podendo ser "deixado de lado" até que algumas violações de direitos sejam completamente resolvidas. A Constituição dispõe sobre a simultaneidade de aplicação do direito ao meio ambiente ecologicamente equilibrado, pois entende que todos os direitos fundamentais são interdependentes e estão inter-relacionados, devendo sempre existir medidas de efetivação para todos os direitos de forma simultânea.

Quanto a terceira teoria existe um possível impasse, já que se questiona a possibilidade de expandir as liberdades, gerando desenvolvimento, sem diminuir a quantidade de meio ambiente ecologicamente equilibrado existente. No entanto, essa é também a questão a missão que a Constituição brasileira deixa a seus interpretes: é possível conciliar, na realidade, desenvolvimento e meio ambiente?

Desta forma, o problema desta terceira teoria seria a efetividade real dela. Afinal, o Brasil está inserido num contexto capitalista, que se carateriza pela busca incessante da maximização dos lucros, o que se dá pela maior produtividade do trabalho e pelo menor custo de produção ${ }^{29}$. Este, por sua vez, é alcançado com a minimização das medidas de proteção ambiental, de segurança e da qualidade das condições de trabalho. É importante ressaltar também que esse sistema é responsável por elevar a destruição dos recursos naturais, pois o objetivo do mercado é alcançar produtos de curta duração, com incentivo ao descarte ao desperdício.

Mas é claro que a Constituição disciplinou a ordem econômica brasileira sob um sistema capitalista, pois traz em si, como princípio da ordem econômica a livreiniciativa e como direito fundamental a propriedade privada. Uma vez que esses valores e direitos entram em conflito com a preservação ambiental, a Constituição apresenta proposta de solução para tal conflito ao determinar à atividade econômica a obrigatória observância do princípio de defesa do meio ambiente e ao condicionar o direito à propriedade privada ao atendimento de sua função social, que é integrada pela dimensão ambiental. É o que se chama de princípio do desenvolvimento sustentáve $^{30}$, que entente compatibilizar a proteção do meio ambiente com o desenvolvimento.

29 WOOD, Ellen Meiksins. O que é (anti) capitalismo? Revista Crítica Marxista. São Paulo: Revan, n.17, p.37-50, 2003.

30 CAMARGO, Ana. Desenvolvimento sustentável: dimensões e desafios. Campinas: Papirus, 2003, p. 65-76. 
Assim, a ordem econômica e os princípios que a regem, especialmente os do art. 170 da Constituição, tornam o Brasil o chamado "capitalismo socioambiental"31 ou ainda uma "economia ecológica social de mercado"32, que seria a ideia do Estado regular a atividade econômica "objetivando o desenvolvimento humano e social de forma ambientalmente sustentável"33.

No entanto, essa conciliação que a Constituição propõe só é possível se os interesses do capital não continuarem a se sobrepor a Carta Magna, e se o Poder Público, diante de determinada realidade, tomar a melhor decisão para os direitos fundamentais sem se olvidar do meio ambiente, se toda a sociedade compreender que cabe a todos proteger o meio ambiente.

Isso é o que se pode chamar de mudança da "microrracionalidade de lucro para uma macrorracionalidade social ecológica” ${ }^{34}$, o que somente será possível se houver uma mudança real no modo de vida, no desenvolvimento tecnológico e, principalmente, nos padrões de consumo, que devem ser pautadas nas necessidades reais da população e na conservação do meio ambiente.

\section{CONSIDERAÇÕES FINAIS}

Tendo em vista que a base do conceito de desenvolvimento de Amartya Sen é a expansão das liberdades, não estando estas necessariamente ligadas ao crescimento econômico, é possível compatibilizar tal teoria com conceitos de desenvolvimento sustentável. No entanto, o maior problema reside na prática, em que o capital se recusa a se submeter aos deveres que o meio ambiente ecologicamente equilibrado impõe.

É possível perceber que a Constituição brasileira tem em si a ânsia por compatibilizar capitalismo, desenvolvimento e proteção do meio ambiente, sendo impossível, nesse contexto, separar as questões ambientais, sociais e éticas da noção de desenvolvimento, isso porque é inviável atender a dignidade humana sem

31 SARLET, Ingo Wolfgang. FENSTERSEIFER, Tiago. Estado socioambiental e mínimo existencial (ecológico?): alguns aproximações. In: SARLET, Ingo Wolfgang (Org.). Estado Socioambiental e Direitos Fundamentais. Porto Alegre: Livraria do Advogado, 2010, p.13.

32 DERANI, Cristiane. Direito Ambiental Econômico. 2. ed. São Paulo: Max Limonad, 2001, p. 246.

33 DERANI, Cristiane. Direito Ambiental Econômico. 2. ed. São Paulo: Max Limonad, 2001, p. 
Saberes da Amazônia | Porto Velho, vol. 03, nº 06, Jan-Jun 2017.

o respeito aos direitos sociais básicos e a uma vida saudável com qualidade de vida. A ideia de desenvolvimento como expansão das liberdades, tem como foco o constante aprimoramento do bem-estar de toda a população e de todos os indivíduos, o que implica também na proteção do meio ambiente, ainda que Amartya Sen não o diga expressamente.

Dessa forma, ainda que haja um enfrentamento aparente dos direitos ao desenvolvimento e ao meio ambiente ecologicamente equilibrado, uma noção de desenvolvimento vinculada a questões éticas, humanistas e inclusivas dos direitos sociais básicos e ao bem-estar ambiental, como pode ser lida a teoria de Amartya Sen, acaba por conformar os aludidos direitos. Conciliados tais direitos, para que haja uma efetivação de tais ideias ainda é preciso conscientizar a sociedade de que é necessário uma mudança de civilização para que o meio ambiente seja de fato protegido.

\section{REFERÊNCIAS DAS FONTES CITADAS}

BARONI, Margaret. Ambigüidades e deficiências do conceito de desenvolvimento sustentável. RAE - Revista de Administração de Empresas, 1992.

BENJAMIN, Antonio Herman V. Constitucionalização do Ambiente e Ecologização da Constituição Brasileira. In CANOTILHO, José Joaquim Gomes; LEITE, José Rubens Morato (Orgs.). Direito Constitucional Ambiental Brasileiro. São Paulo: Saraiva, 2007.

BENJAMIN, Antonio Herman. Função Ambiental. Brasília: BDJUR, 1993.

CAMARGO, Ana. Desenvolvimento sustentável: dimensões e desafios. Campinas: Papirus, 2003.

CANOTILHO, J.J. Gomes. Direito Constitucional Ambiental Português e da União Europeia. In: CANOTILHO, José Joaquim Gomes; LEITE, José Rubens Morato (Orgs.). Direito Constitucional Ambiental Brasileiro. São Paulo: Saraiva, 2007.

FERREIRA, Heline Sivini. LEITE, José Rubens Morato. A expressão dos objetivos do Estado de Direito Ambiental na Constituição Federal de 1988. In: COUTINHO, Ronaldo; AHMED, Flávio. Cidade, direito e meio ambiente: perspectivas críticas. Rio de Janeiro: Lumen Juris, 2011.

GALILEU. Disponível em: http://revistagalileu.globo.com/Revista/Common/0,ERT214178-17773,00.html>. Acesso em: 10 nov. 2016.

SARLET, Ingo Wolfgang. FENSTERSEIFER, Tiago. Estado socioambiental e mínimo existencial (ecológico?): alguns aproximações. In: SARLET, Ingo Wolfgang (Org.). Estado Socioambiental e Direitos Fundamentais. Porto Alegre: Livraria do Advogado, 
2010.

SEN, Amartya. Desenvolvimento como liberdade. São Paulo: Companhia das Letras, 2000.

SILVA, José Afonso da. Curso de Direito Constitucional Positivo. 22. ed. São Paulo:Malheiros, 2003.

STF - MS 22.164 - Rel. Min. Celso de Mello - Distrito Federal - j. em 17.11.1995. Disponível em: <http://www.stf.gov.br/jurisprudencia>. A cesso em 10 nov. 2016.

TRINDADE, Antonio Augusto Cançado. Direitos Humanos e Meio Ambiente: Paralelo dos sitemas de Proteção Internacional. Porto Alegre: Sergio Antonio Fabris, 1993.

VEIGA, José Eli da. A emergência socioambiental. São Paulo: Senac, 2007.

WOOD, Ellen Meiksins. O que é (anti) capitalismo? Revista Crítica Marxista. São Paulo: Revan, n.17, p.37-50, 2003. 